\title{
Using Blueprints to promote interorganizational knowledge transfer in digital health initiatives-a qualitative exploration of a national change program in English hospitals
}

\author{
Robin Williams, ${ }^{1}$ Aziz Sheikh, ${ }^{2}$ Bryony Dean Franklin, ${ }^{3}$ Marta Krasuska ${ }^{2}{ }^{2}$ Hung The \\ Nguyen, ${ }^{1}$ Susan Hinder, ${ }^{1}$ Wendy Lane, ${ }^{4}$ Hajar Mozaffar, ${ }^{5}$ Kathy Mason, ${ }^{4}$ Sally Eason, ${ }^{4}$ \\ Henry W. W. Potts, ${ }^{6}$ and Kathrin Cresswell ${ }^{2 *}$
}

\begin{abstract}
${ }^{1}$ Institute for the Study of Science, Technology and Innovation, The University of Edinburgh, Edinburgh, UK, ${ }^{2}$ Usher Institute, The University of Edinburgh, Edinburgh, UK, ${ }^{3}$ University College London, London, UK, ${ }^{4}$ National Health Services Arden and Greater East Midlands Commissioning Support Unit, Warwick, UK, ${ }^{5}$ Business School, The University of Edinburgh, Edinburgh, UK, and ${ }^{6}$ University College London, London, UK

*Corresponding Author: Kathrin Cresswell, PhD, Usher Institute, University of Edinburgh, Old Medical School, Teviot Place, Edinburgh EH8 9AG, UK (kathrin.cresswell@ed.ac.uk)
\end{abstract}

Received 2 0ctober 2020; Revised 18 January 2021; Editorial Decision 25 January 2021; Accepted 8 February 2021

\begin{abstract}
Objective: The Global Digital Exemplar (GDE) Program is a national attempt to accelerate digital maturity in healthcare providers through promoting knowledge transfer across the English National Health Service (NHS). "Blueprints" — documents capturing implementation experience-were intended to facilitate this knowledge transfer. Here we explore how Blueprints have been conceptualized, produced, and used to promote interorganizational knowledge transfer across the NHS.

Materials and Methods: We undertook an independent national qualitative evaluation of the GDE Program. This involved collecting data using semistructured interviews with implementation staff and clinical leaders in provider organizations, nonparticipant observation of meetings, and key documents. We also attended a range of national meetings and conferences, interviewed national program managers, and analyzed a range of policy documents. Our analysis drew on sociotechnical principles, combining deductive and inductive methods.

Results: Data comprised 508 interviews, 163 observed meetings, and analysis of 325 documents. We found little evidence of Blueprints being adopted in the manner originally conceived by national program managers. However, they proved effective in different ways to those planned. As well as providing a helpful initial guide to a topic, we found that Blueprints served as a method of identifying relevant expertise that paved the way for subsequent discussions and richer knowledge transfers amongst provider organizations. The primary value of Blueprinting, therefore, seemed to be its role as a networking tool. Members of different organizations came together in developing, applying, and sustaining Blueprints through bilateral conversations-in some circumstances also fostering informal communities of practice.

Conclusions: Blueprints may be effective in facilitating knowledge transfer among healthcare organizations, but need to be accompanied by other evolving methods, such as site visits and other networking activities, to iteratively transfer knowledge and experience.
\end{abstract}

Key words: Blueprints, digital transformation, hospital, knowledge transformation, learning ecosystem

(C) The Author(s) 2021. Published by 0xford University Press on behalf of the American Medical Informatics Association.

This is an Open Access article distributed under the terms of the Creative Commons Attribution Non-Commercial License (http://creativecommons.org/licenses/by-nc/4.0/), which permits non-commercial re-use, distribution, and reproduction in any medium, provided the original work is properly cited. For commercial re-use, please contact journals.permissions@oup.com 


\section{INTRODUCTION}

There is an international policy drive to implement health information technology (HIT). However, there is currently no clear understanding of how to achieve adoption of best practice solutions at scale and share the information and knowledge needed for this. ${ }^{1,2}$ The existing empirical literature on knowledge transfer between healthcare organizations is limited, particularly in relation to digital transformation, and most evidence comes from commercial settings. ${ }^{3-7}$ Here, studies have shown that transfer of codified knowledge through documents can save time, but the effectiveness of this process depends on the task at hand. ${ }^{8}$ We here report on a study evaluating a large HIT change program in England.

The English Global Digital Exemplar (GDE) Program represents an ambitious attempt to establish a digital health learning ecosystem at national scale. ${ }^{9}$ It sought to advance digital transformation in selected digitally mature provider organizations (hereafter GDEs) and then ensure that successful improvements were shared across the GDE Program and more widely across the English National Health Service (NHS). A key intended mechanism for achieving knowledge transfer was through the production of "Blueprints", documents that contain implementation knowledge. The Program's architects envisaged that GDE sites would "partner with other hospitals as their Fast Followers (FFs) and develop Blueprints that take the insights and deployment experience of the GDEs and core technical 'build' of their system and work with these FF organizations to implement Blueprints." 10

Blueprints were thus proposed as the key vehicles for conveying the knowledge needed to select and implement "proven" models of change. Digitally mature GDE sites would develop a portfolio of digital changes and produce Blueprints capturing the technical (eg, technological infrastructure, data structures) and strategic (eg, organizational change, engagement, training) details needed to implement a similar change in less mature FFs. They would produce "technology-agnostic" Blueprints (eg, detailing strategic information that is not specific to a certain system [eg, approaches to user engagement]), or "technology-specific" Blueprints (ie, coding and other information specifically related to the implementation and optimization of particular applications). The production of Blueprints was required under the agreements for funding ( $£ 10$ Million for GDEs and $£ 5$ Million for FFs) under the GDE Program. Blueprints were held in a central digital library administered by the GDE Program and accessible to all GDEs and FFs.

Blueprints were initially proposed as a means for standardizing procurement around proven solutions, saving the time and cost of each organization learning from scratch. ${ }^{11}$ There is to date no empirical evidence that this kind of approach will succeed in the context of digitizing health systems. ${ }^{12}$ Reflecting on the limited success of earlier centralized national programs to spread good practice across the NHS, an influential 2016 national review by Robert Wachter argued that to harness the power of HIT we cannot "simply follow a recipe or a checklist". Instead, this kind of "adaptive change" requires "substantial and long-lasting engagement between those implementing the changes and the individuals tasked with making them work". ${ }^{13}$ The conception of Blueprints evolved significantly during the GDE Program, with new formats and tools developed to facilitate their wider uptake and use. However, a recent National Audit Office report on digital transformation in the NHS raised concerns that Blueprints "might not be enough to spread good practice... to other [provider organizations] as intended". ${ }^{14}$
We were commissioned to conduct an independent formative evaluation of the GDE Program. ${ }^{15}$ In this article, we explore the production and uptake of Blueprints, aiming to gain insights into if and how they have facilitated knowledge transfer among GDE and FF provider organizations.

\section{MATERIALS AND METHODS}

We conducted a qualitative evaluation consisting of semistructured interviews, ethnographic observations, and documentary analyses. Data collection took place longitudinally between March 2018 and March 2020. The detailed methodology for the independent qualitative evaluation of the GDE Program is described in a separate protocol. ${ }^{16}$

\section{Setting}

We sampled 12 UK provider organizations for maximum variation (eg, size, type, location, core system provider) for in-depth study (Table 1). ${ }^{17}$ These in-depth case studies were designed to provide deep insights into local processes and contexts. We also collected less detailed data in a further 24 UK provider organizations. These broader case studies enabled us to test emerging findings from the in-depth case studies in a wider range of sites. Details of the whole sample of provider organizations involved are provided in a related article. ${ }^{18}$ We here distinguish between organizations that implemented a large organization-wide electronic health record system and those that had secured the required functionality from a range of different suppliers and knitted these systems together to form a so-called "Best-of-Breed" technological infrastructure.

\section{Sampling of participants}

Purposive sampling was used to identify the appropriate individual participants in each of the in-depth case study sites with the help of local gatekeepers (chief information officers or equivalent). In doing so, we sought to consult participants in management/leadership roles that were involved in delivering local digital transformation associated with the GDE Program. They included local program managers, clinical leaders, and information technology staff. In order to gain insights into the wider strategic landscape, we also used purposive sampling for wider key stakeholders including NHS policy makers, national program management staff, system vendors, the wider NHS, international hospitals and partner organizations, and academics. Individuals gave informed verbal consent to participate and did not receive compensation for their participation.

\section{Data collection}

We conducted a series of ethnographic nonparticipant observations of local meetings and practices and in-depth interviews with implementation staff over an extended timeframe in each in-depth case study site. We also observed national program management meetings and conducted in-depth semistructured interviews with program managers, policy makers, vendors, international hospitals and partner organizations, and academics. These explored how Blueprints were planned, produced, and used as part of the GDE Program and how this affected provider organizations (Box 1). These also helped us to explore policy learning in the course of the Program. The full topic guide can be viewed in the published protocol. $^{16}$ We provide an overview of observation guide for nonparticipant observations in Box 2. 
Table 1. Summary features of in-depth case study sites

\begin{tabular}{|c|c|c|c|c|}
\hline & Provider Organization & Type & Systems & Geographical Area in the UK \\
\hline Site A & $>10000$ staff & Acute & Large enterprise system & Midlands and East \\
\hline Site B & $<2000$ staff & Acute & Large enterprise system & North \\
\hline Site C & $>10000$ staff & Specialist & Large enterprise system & South \\
\hline Site D & $>4000$ staff & Acute & Best-of-Breed & South \\
\hline Site E & $>4000$ staff & Acute & Large enterprise system & South \\
\hline Site F & $>4000$ staff & Mental health & Best-of-Breed & Midlands \& East \\
\hline Site G & $>10000$ staff & Mental health & Large enterprise system & North \\
\hline Site H & $>4000$ staff & Acute & Large enterprise system & North \\
\hline Site I & $>10000$ staff & Acute & Large enterprise system & South \\
\hline Site J & $>4000$ staff & Acute & Large enterprise system & North \\
\hline Site L & $>4000$ staff & Acute & Large enterprise system & South \\
\hline Site M & $<2000$ staff & Acute & Best-of-Breed & Midlands \& East \\
\hline
\end{tabular}

\section{Box 1: Interview topic guide exploring the production and use of Blueprints}

- How are you/your organization involved in Blueprint production and use?

- What are your experiences of the Blueprinting process (challenges, areas for improvement)?

- Who has used Blueprints and how have they found them useful?

- Can you give us some practical examples of how you have used Blueprints?

- What ways of use have you found to be most productive?

- What could be changed to maximize the benefits of Blueprints?

\section{Box 2: Topic guide for nonparticipant observations}

- Description of the layout of the room and the way participants move

- Description of the actors and what they do

- Insights into process-how Blueprints are conceived, implemented, and used

- Insights into outcome-practice/skills, workflow, behavior/attitudes

- Reactions of actors to specific questions

- Researcher impressions/feelings in relation to the observation

We further collected documents relating to local implementation plans, lessons learned, and national progress and management processes in order to gain insights into local and national plans and progress against milestones.

Interviews were digitally recorded, transcribed by a professional transcriber, and, together with ethnographic field notes from observations and documents, coded by the research team with the help of NVivo software. ${ }^{19}$

Our core dataset comprised 457 interviews, 86 observations, and analysis of 245 documents in the 36 provider organizations (Table 2). We also conducted 51 interviews, observed 77 meetings, and collected 80 documents with other stakeholders. Results are discussed according to 3 key themes identified.

\section{Analysis}

We conducted a theoretically informed thematic analysis of the data drawing on sociotechnical theory. ${ }^{20-23}$ This helped to conceptualize how the technological and social dimensions of change were closely interrelated and shaped each other over time. The sociotechnical approach moves away from simplistic conceptions of technology as driving organizational change to explore the close interplay between technological, organizational, and social dimensions in shaping the design and implementation of technological systems and their organizational outcomes.

Initially, researchers coded their own data (interviews, documents, observations) within cases, followed by detailed cross-case analysis involving all authors. Analysis began with induction from the corpus of in-depth interviews to explore the detailed mechanisms and processes involved in producing and using Blueprints. Data from documents and observations was used to provide additional context (documents) and to gain insights into interpersonal dynamics associated with knowledge sharing.

In doing so, we examined a subset of the data in detail to examine Blueprinting processes (ie, those where the term Blueprinting was explicitly mentioned) but placed these within the wider context of Program processes, as it became apparent that these were key in influencing how Blueprints were produced and used.

Emerging themes were fed back into subsequent data collection to test and refine emerging findings. This resulted in some minor 


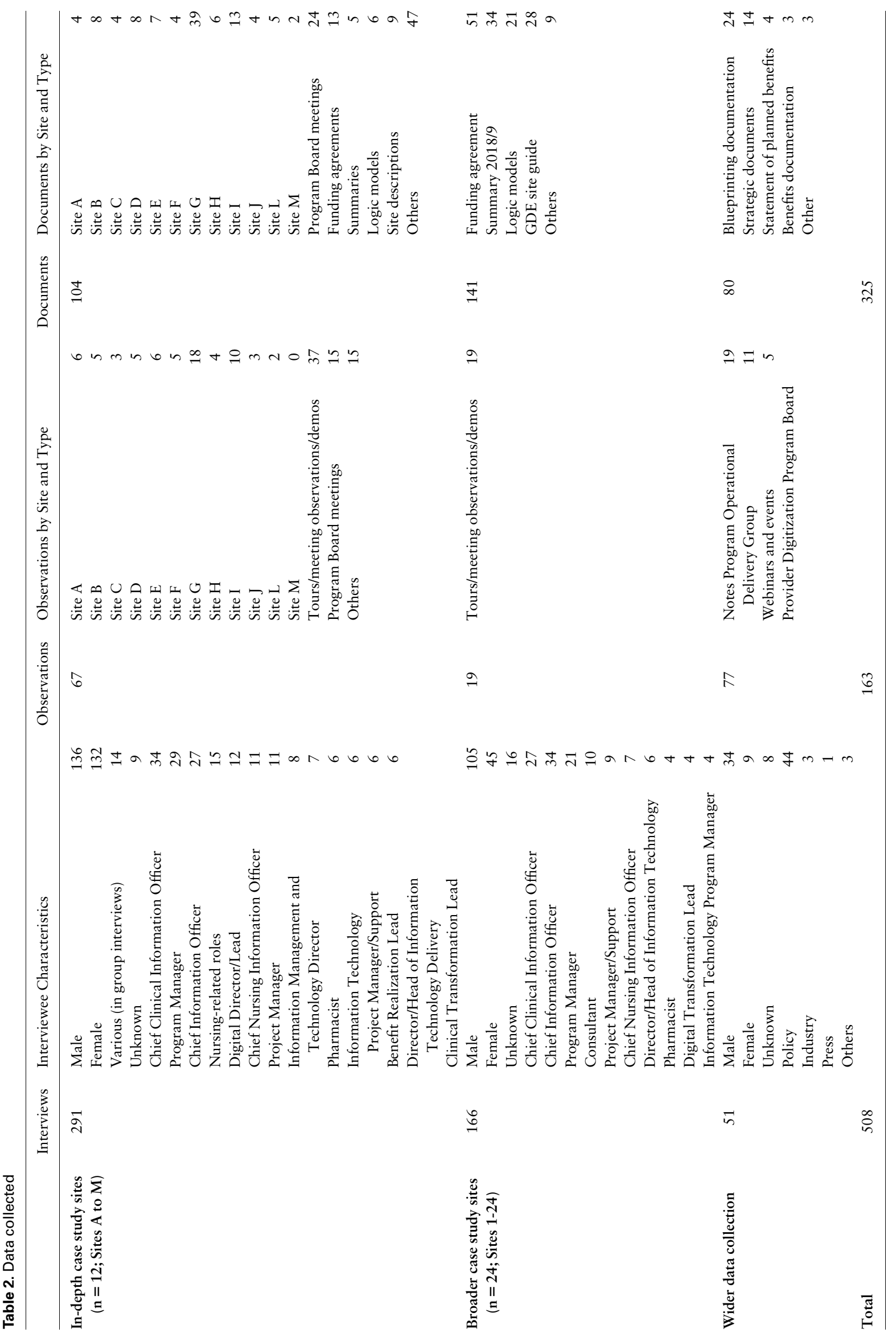


revisions to the topic guide (mainly in relation to adding specific prompts relating to the Blueprinting process), and it also helped us to target particular interviewees who were involved in Blueprinting activity. We developed an analytical narrative through a series of intensive analysis workshops with the wider research team, paying particular attention to contradicting findings and emerging tensions. We used researcher triangulation to verify consistency and agreement on coding throughout the process.

Coding and analysis were informed by a sociotechnical understanding of the implementation of HIT and an earlier body of related research addressing social learning processes in technological change in other settings. ${ }^{20,21}$ The codebook, which was based on a theoretical framework of sociotechnical dimensions of digital transformation in healthcare, is attached in Supplementary Appendix S1. ${ }^{21}$

\section{Ethics approval}

We obtained institutional ethics approval from the School of Social and Political Science at The University of Edinburgh, UK.

\section{RESULTS}

Three key themes emerged from our analysis: 1) From Blueprints to Blueprinting: the evolving conceptualization of Blueprints over time; 2) The production of Blueprints; and 3) The use of Blueprints including unanticipated use as a networking tool. These will be explored in more detail in the subsequent paragraphs.

\section{From Blueprints to Blueprinting: the evolving conceptualization of Blueprints over time}

The concept of Blueprints changed, over time, as they were developed and used. They were initially conceived as tools to help standardize products and processes, where a few specific sites would develop, test, and optimize proven models for digital change that would then be rolled out across the NHS. ${ }^{11}$ This "cookie-cutter" view of standardized procurement was borrowed from the construction and engineering industries where the term "Blueprint" refers to a method for accurately copying technical drawings by making contact prints on light sensitive paper. ${ }^{24}$

Following engagement with Blueprint producers and users from GDE and FF sites, a strikingly different conception emerged of how Blueprints could function as a vehicle for knowledge transfer-as "live documents that drive people wanting to benefit from GDE experiences to seek further information". ${ }^{25}$ It highlighted that Blueprints "can be viewed through a range of lenses", in part due to the differing requirements of "different audiences" (hospital boards, Chief Information Officers (CIOs), implementation and clinical teams). Boards, for example, might look for technology-agnostic Blueprints, while technology implementation teams would find value in technology-specific Blueprints. ${ }^{26}$ Thus Blueprints would be "story-like- a compelling narrative of actions and events..." that could "instruct without dictating [and] accommodate the adaptive component of change". ${ }^{27}$ This pointed to significant process of policy learning in the course of the GDE Program involving policymakers and provider organizations.

However, these competing conceptions and changes over time in the model of how Blueprints would convey learning created difficulties for the provider organizations charged with implementing the Blueprinting concept. Site A's Digital Lead flagged a key uncertainty about the intended role of the Blueprint, noting that "right at the very beginning it wasn't clear" whether the intention was that sites would produce a "high level piece" with generally applicable lessons on how to achieve a digital change or a more detailed prescriptive guidance on "how you do it" for implementing that change within a particular technology platform. Many sites pointed out that their initial implementation experiences would be rooted in their particular organizational and technological context. As a result, the lessons drawn in their Blueprints were liable to be technology- and organization-specific. This would increase their relevance/value for similar sites but limit their transferability. Thus, Site C's Information Management and Technology (IM\&T) Lead flagged that they could produce specific guidance that would be "immediately available" for other sites working with the same platform, as it "doesn't have to be redone from scratch and I think that has huge value". Likewise, Site A's Digital Hospital Lead noted that for another site with the same version of their platform "I could send them the actual configuration that they could import". While technology-specific Blueprints might have great relevance to organizations with similar technology and processes, these might not be widely applicable or readily transferable to other sites. Site 20 noted that 6 of the GDE sites had adopted Cerner Millennium, which had created scope among this cohort to exchange very detailed platform-specific configurations. Site L (also a Cerner site) had been able to draw on workflows developed by another provider organization including sharing code through the Cerner platform: "Taking the code that they've developed and using it in our [provider organization]". In turn, Site L had been approached by other Cerner sites that were able to adopt their Blueprint (for a specific function), but noted that these lessons would be irrelevant for non-Cerner sites.

The CIO in Site F felt that "the Blueprint has to be contextual. . unique to every care setting [in terms of systems and how my environment works] ... so to some extent, it's very difficult to take a Blueprint out and drop it somewhere". For example, "a process I'd done on [specific application] that would only be really, really applicable to some other [provider organization] on [specific application]".

\section{The production of Blueprints}

There was widespread support across the Program for the idea of Blueprints-at least in principle-driven by a shared commitment to the collective desire for the success of the NHS and a consequent concern to support and share expertise and experience with those organizations that were not part of the GDE Program. "I think Blueprints are a great idea.... I'm very supportive of the Blueprint principle" (Site A, Chief Clinical Information Officer [CCIO]); " $a$ great concept" (Site M, Senior Project Lead); "the concept of Blueprinting is really positive" (Site B, Digital Program Manager); "a tangible output out of GDE to support those sites that aren't on $G D E$ ” (Site B, Program Manager).

This near unanimous enthusiasm for the principle of Blueprints was tempered, however, by equally prevalent doubts about whether the costs-in terms of the time and effort of organizational members producing them-would be justified in relation to their benefits in terms of how widely used and how useful Blueprints would be.

At the start of the Program, when GDE sites were preoccupied with procuring and implementing new digital solutions, the production of Blueprints was often set aside for later. Site I Project Manager noted that "weve been too busy doing it...to actually Blueprint it". At this site, production of Blueprints only occurred upon completion of their GDE projects. 
Many sites also emphasized the large amount of work required to create a Blueprint and associated documentation. Site I's Digital Change Manager told us "I didn't really realize how big of a job it was going to be. And like trying to juggle that, as well as your dayto-day activity, that has been a challenge". At Site B, the Chief Clinical Information Officer felt "Blueprinting has taken a massive chunk of time”, while the Clinical Transformation Lead noted that writing the Blueprinting document "was taking over my life. It's a buge amount of effort and work ... the only way I could do it was I stayed late after work".

Notwithstanding these costs, the CCIO at Site I drew our attention to an unanticipated benefit of producing the Blueprint which had forced them "to reflect on what you do. And, I'm sure there are a huge number of lessons that we've surfaced, having read the draft Blueprint, that will be really beneficial for other people". And this had also benefitted them: "we're sort of now retro-fitting some of our lessons, but forcing us to think about them, forces us to continue to go back and improve it". Given the time pressure and work required "we probably wouldn't have bothered, if we didn't have to [analyst emphasis] write a Blueprint".

The majority of sites were at the time of interviews not convinced about the utility of Blueprints and their value as a vehicle for knowledge transfer. Thus, Site F's CIO judged that Blueprints were only "useful to a very limited extent". Site C's IM\&T Lead expressed concern that "Blueprinting stuff is a waste of time, [be]cause, essentially, people are spending quite a lot of time writing stuff up, and it'll sit in a library and the people who need to use it, won't use it". As a result, the investment may not be warranted: "I'm not sure how much they're actually used so, I think, there's quite a lot of money and time going into things that are probably not sensible" (Site C, IM\&T). Similar concerns were expressed by Site I's Project Manager about the effort invested in producing " $a 20$ 000- to 30,000-word document, that I don't know who's going to read".

Site B's IM\&T Lead noted that the jury is still out "about how useful they are". More work and better understanding would be needed to create Blueprints that would be widely adopted at "scale and pace” (Site L, CIO).

\section{The use of Blueprints including unanticipated use as a networking tool}

The vast majority of sites ( 27 of 36 covered in case studies) did not report using Blueprints as a vehicle for acquiring the knowledge needed to implement change. Two sites (Site 10 and Site 22) indicated that they were planning to use others' Blueprints in the future. Many other sites reported that they had reviewed the Blueprints but not adopted them. Several observed that the Blueprints had arrived too late for them to adopt and were not aligned with the digital transformation journey they had by then developed.

Others found Blueprints from other sites useful. FF sites B and 23 had followed the approaches that their GDE had adopted and subsequently blueprinted (an observation that implies that the Blueprint itself was not the vehicle for their learning). They had not adopted Blueprints from other sites. Site 3 identified 4 specific Blueprints they had learnt from, which helped them accelerate change and avoid mistakes.

"I have read a few and I found them ... actually quite useful. So, I sort of changed my mind on them ... I've reviewed quite a number. I found [named Blueprint] very helpful.... some of them include costs, which is useful, to give us a steer on how much investment we might be needed before we start embarking upon them."

However, it is important to keep in mind that use is not the same as adoption. For instance, Site 14 decided against adopting a particular change after reading a Blueprint that was honest and candid about the difficulties and costs entailed.

Although there was little evidence that Blueprints were working in the way originally planned-as a vehicle for delivering the knowledge needed to implement a change-they were proving helpful in other ways. Provider organizations used them not only as an initial introduction to a particular area of change, but also, and more significantly, as a way of contacting the people involved. Thus, their main value was perceived to be as a networking tool.

As Site M, GDE Project Manager noted: "part of it is that you've got contact details and ... you undertake to make yourself available to other organizations. . . So, it's a sort of networking tool."

The Head of Hospital at Site A suggested that Blueprints were "just the distillation of often the conversations that we're having with lots of hospitals anyway." They could never "be a truly onestop shop" for other sites which, due to differing circumstances, would have different issues to raise. "I view the Blueprints as a really good starting point ... but then there will always be some sort of follow-up conversation." The Chief Nursing Information Officer (CNIO) at Site A also observed that "the Blueprint is there just to start the conversation" noting that seeing things was more useful for understanding than "reading it on a piece of paper". Several Sites (Sites 3, 9, 17 and 18) shared this view that visits and interactive conversations were more valuable in transferring these kinds of complex knowledge than a piece of paper, particularly in communicating important cultural factors. Site visits were particularly effective because they provided an opportunity to address the differing circumstance of sites and other factors that might readily be overlooked.

Many other respondents observed that it was these contacts and visits that brought the greatest benefit. At Site D, the CNIO observed, "the most benefit you get is that contact with other people", while the $\mathrm{CIO}$ flagged benefits for when provider organizations from "come and visit us and we talk ... and share". This was in part because the Blueprint could only convey a limited amount of information. An Allied Health Professional at Site C felt that Blueprints were not detailed enough from a user perspective: "I'm not convinced there is enough detail to really drill down" but noted that this was not a problem however "as long as they've got contact details... most people in this space are very willing to share and collaborate". A similar perspective from a Blueprint producer came from the Assistant Director of Program Delivery at FF Site L who noted that "there is a limit to how much technical stuff you can put on a Blueprint". Instead, sites will "get in touch with us and maybe come over and have a look at it".

\section{DISCUSSION}

\section{Summary of findings}

Blueprints have facilitated knowledge transfer among GDE and FF organizations and beyond. However, we found limited evidence that Blueprints were being adopted and used in the way initially envisaged (as a vehicle for the wholesale transfer of the knowledge needed to successfully implement a particular innovation). Our respondents drew attention to ways in which Blueprints were being used and proving useful in other ways. They acted as repositories for 
codified knowledge but were most successful where their role in formal knowledge transfer led on to, and was supplemented by, informal knowledge sharing and linking together stakeholders interested in a particular implementation.

\section{Strengths and limitations}

Our independent evaluation gave us a unique opportunity to examine Blueprinting from the viewpoint of those involved in producing them, who were also the intended early adopters. Our methodology, based primarily on intensive longitudinal case studies and annually repeated broader case studies of GDE/FF sites, was designed to evaluate a policy initiative to promote knowledge transfer across a group of organizations and draw insights from examining variations across the Program and the reflections of actors involved rather than, for example, focusing on details of knowledge transfer within a particular partnership. Our point of access to particular providers did not allow us to track knowledge transfer around individual Blueprints-including cycles of adoption and refinement of Blueprints and community formation around Blueprints.

It is difficult to track the process and outcomes of knowledge transfer (and particularly informal knowledge sharing). There is therefore a risk that attempts to measure impact will underestimate the benefit of Blueprinting activity. If evaluation methods revolve around a narrow conception of how Blueprints should be used and prove useful, they may fail to capture the indirect benefits of sharing and informal networking activities. We need also to consider the methodological difficulties in tracking the use of knowledge outputs like Blueprints-particularly among wider audiences beyond the GDE Program. ${ }^{28}$

Although we found little evidence of the use of Blueprints in the first year after they were launched, this may overlook subsequent growth in uptake and does not rule out the possibility for subsequent growth. Blueprints were piloted in 2018, and full-scale rollout took place in 2019 (rather late in the life of the GDE Program). Our in-depth studies record developments to early 2020 but the second round of our broader case study findings were completed in the summer of 2019. Increasing uptake may be anticipated over time, perhaps accelerated by the recent relaunch of the Blueprinting platform (see below).

\section{Contextualization of findings in the current literature}

Our results question the value of creating Blueprints to promote interorganizational knowledge transfer based on the perceived high effort of producing them and their perceived limited utility. However, the concept of Blueprints evolved over time and important changes were subsequently introduced to redress this. These changes may reflect the general uncertainty of how best to promote interorganizational knowledge transfer. ${ }^{8,29,30}$ Commercial settings have similarly struggled to establish in what contexts transfer of codified knowledge and documents is likely to be effective. ${ }^{8}$ We have shown that it is difficult to transfer codified knowledge from 1 setting to another productively (eg, by circulating Blueprints). Organizational contexts differ-hence the importance of transferring embodied knowledge through networking and secondments. ${ }^{31}$ The transfer of codified knowledge may be more effective with common technological platforms/systems.

Dissemination of knowledge to other settings and its integration into practice proved difficult and is most likely to be promoted through a combination of methods, ${ }^{32,33}$ including informal networking and face-to-face meetings, site visits and personnel trans- fers, and promoting the formation of networks, communities, and alliances. ${ }^{7,34-37}$ This explains the unanticipated use of Blueprints as a networking tool, which is in line with findings that informal and social networks are most effective in transfer of knowledge. ${ }^{38,39}$

\section{Implications for policy and practice emerging from this work}

We found evidence of important policy learning in the course of the Program. In particular, the template and process for creating Blueprints was piloted and improved continuously, responding to feedback received from implementing organizations which, for example highlighted usability and access issues with the technology platform used for sharing them. New search tools and more accessible formats have recently been introduced-such as a "Blueprint on a Page", technical annexes, and a library of potentially reusable modular components (for example, information governance arrangements or a safety case) that might provide a solution to a particular problem facing many other adopters.

Blueprints have helped to promote a digital health learning ecosystem in the NHS. ${ }^{40}$ They are most likely to be successful when integrated with other mechanisms of knowledge transfer to promote systemic change. The contribution of these formal knowledge transfer mechanisms (Blueprinting and the partnerships between GDEs and FFs) supported by the GDE Program, and the consequent increase in salience of informal networking, must be viewed as part of a broader set of changes across the health service. ${ }^{41-44}$

\section{CONCLUSIONS}

Documents capturing implementation experience (such as Blueprints) may offer helpful introductions to a field and generic highlevel guidance but cannot provide all the knowledge needed for implementing digital change in another site with its (different) particular technological and organizational circumstances. We found that would-be adopters therefore found Blueprints useful not primarily as a knowledge repository but crucially as a networking tool-as a means to identify and contact colleagues elsewhere who had implemented a change in their own organizations. Through direct interactions, complex implementation experience could be transferred to different settings and "translated" to address local contingencies. Formal knowledge transfer mechanisms thus enabled and in turn were strongly supported by crucial informal knowledge sharing activities-and in this way contributed to the development of a digital health learning ecosystem.

\section{FUNDING}

This article has drawn on a program of independent research funded by NHS England. The views expressed are those of the author(s) and not necessarily those of the NHS, NHS England, or NHS Digital. This work was also supported by the National Institute for Health Research (NIHR) Imperial Patient Safety Translational Research Centre.

\section{AUTHOR CONTRIBUTIONS}

RW and KC conceived this article. RW and KC led the drafting of the manuscript and all authors commented on drafts of the manuscript. 


\section{SUPPLEMENTARY MATERIAL}

Supplementary material is available at Journal of the American Medical Informatics Association online.

\section{ACKNOWLEDGMENTS}

We gratefully acknowledge the input of the participants and the Steering Group of this evaluation.

\section{DATA AVAILABILITY}

The data underlying this article cannot be shared publicly to protect the anonymity of individuals that participated in the study. The data will be shared on reasonable request to the corresponding author.

\section{CONFLICT OF INTEREST STATEMENT}

All authors are investigators on the evaluation of the GDE program (https://www.ed.ac.uk/usher/digital-exemplars). AS was a member of the Working Group that produced Making IT Work, and was an assessor in selecting GDE sites. BDF supervises a $\mathrm{PhD}$ student partly funded by Cerner, unrelated to this article.

\section{REFERENCES}

1. Hendy J, Reeves BC, Fulop N, Hutchings A, Masseria C. Challenges to implementing the national programme for information technology (NPfIT): a qualitative study. BMJ 2005; 331 (7512): 331-6.

2. Blumenthal D. Launching hitech. N Engl J Med 2010; 362 (5): 382-5.

3. The Breakthrough Series: IHI's Collaborative Model for Achieving Breakthrough Improvement. http://www.ihi.org/resources/Pages/IHIWhitePapers/TheBreakthroughSeriesIHIsCollaborativeModelforAchievingBreakthroughImprovement.aspxAccessed August 01, 2020

4. Fincham R, Fleck J, Procter R, et al. Information Technology Strategies in the Financial Services Sector. Oxford: Oxford University Press, 1995.

5. Koch C. ERP Software packages: between mass-production communities and intra-organizational political processes. In: Laurila J, Preece D, eds. Technological Change and Organizational Action. London: Routledge; 2003: 70-90.

6. Mozaffar H. Entangled biographies: A multi-biographical approach in study of user communities around information infrastructures. In proceedings of the ECRM 2018 17th European Conference on Research Methods in Business and Management; July 12-13, 2018; Rome, Italy: The University of Roma.

7. Mozaffar H. User communities as multi-functional spaces: innovation, collective voice, demand articulation, peer informing and professional identity (and more). In: Hyysalo S, Jensen TE, Oudshoorn N, eds. The New Production of Users. London: Routledge; 2016: 219-46.

8. Haas MR, Hansen MT. Different knowledge, different benefits: Toward a productivity perspective on knowledge sharing in organizations. Strat Mgmt J 2007; 28 (11): 1133-53. Nov

9. National Health Service. Global digital exemplars. https://www.england. nhs.uk/digitaltechnology/connecteddigitalsystems/exemplars/Accessed August 01, 2020

10. Swindells M, Smart W. Progressing the acute global digital exemplar. 2017. https://www.england.nhs.uk/blog/progressing-the-acute-global-digital-exemplar/Accessed August 01, 2020.

11. Hanseth O, Bygstad B. Flexible generification: ICT standardization strategies and service innovation in health care. Eur J Inform Syst 2015; 24 (6): 645-19.

12. Stevens L. GDEs should remove need for procurements, says Swindells. Digital Health 2017. https://www.digitalhealth.net/2017/07/gdes-willchange-procurement-models-swindells/ Accessed August 01, 2020
13. Making IT work: Harnessing the power of health information technology to improve Care in England. Report of National Advisory Group on Health Information Technology in England. 2016. https://assets.publishing.service.gov.uk/government/uploads/system/uploads/attachment_data/ file/550866/Wachter_Review_Accessible.pdf Accessed January 8, 2020

14. Digital Transformation in the NHS. https://www.nao.org.uk/report/theuse-of-digital-technology-in-the-nhs/Accessed August 01, 2020

15. Global Digital Exemplar Programme Evaluation. Available from: https:// www.ed.ac.uk/usher/digital-exemplars Accessed August 01, 2020.

16. Cresswell K, Sheikh A, Franklin BD, et al. Formative independent evaluation of a digital change programme in the English National Health Service: study protocol for a longitudinal qualitative study. BMJ Open 2020; 10 (10): e041275.

17. Crowe S, Cresswell K, Robertson A, Huby G, Avery A, Sheikh A. The case study approach. BMC Med Res Methodol 2011; 11 (1): 100.

18. Hinder S, Cresswell K, Krasuska M, et al. Promoting inter-organisational knowledge sharing: a qualitative evaluation of England's Global Digital Exemplar and Fast Follower Programme (submitted to PLOS ONE). https://www.ed.ac.uk/files/atoms/files/second_year_report_gde_evaluation_programme_120220_0.pdf.

19. NVivo. https://www.qsrinternational.com/nvivo-qualitative-data-analysis-software/home Accessed August 01, 2020

20. Williams R, Stewart J, Slack R. Social Learning in Technological Innovation: Experimenting with Information and Communication Technologies. Aldershot, UK: Edward Elgar; 2005.

21. Cresswell K, Williams R, Sheikh A. Developing and applying a formative evaluation framework for health information technology implementations: qualitative investigation. J Med Internet Res 2020; 22 (6): e15068.

22. Bostrom RP, Heinen JS. MIS problems and failures: a socio-technical perspective. Part I: The causes. MIS Q 1977; 1 (3): 17-32. Sep

23. Kling R. Social analyses of computing: theoretical perspectives in recent empirical research. ACM Comput Surv 1980; 12 (1): 61-110.

24. Wikipedia. Blueprint. https://en.wikipedia.org/wiki/Blueprint Accessed August 01, 2020

25. National Health Service. Global Digital Exemplars: Blueprinting update and next steps, presentation for e-Health Week. https://www. ehealthweek.himss-uk.org/sites/ehealthweek/files/sponsors/presentations/ GDE_1/paul_charnley_-_blueprinting.pdf Accessed August 01, 2020

26. National Health Service. What are Blueprints and how will NHS trusts benefit? https://www.england.nhs.uk/expo/wp-content/uploads/sites/18/ 2018/09/13.30-Leapfrog.-how-Global-Digital-Exemplar-Blueprints-canaccelerate-your-transformation-T2K.pdf Accessed January 8, 2020

27. Health Catalyst (2018) Presentation for NHS England Blueprinting Workshop January 2018 (confidential draft).

28. The AHSN Network; GDE Learning Networks - Project Overview May v0.1. Slideset, title GDE Learning Networks project.

29. Secundo G, Toma A, Schiuma G, Passiante G. Knowledge transfer in open innovation. BPMJ 2019; 25 (1): 144-63. Feb

30. Stephanie L, Sharma RS. Digital health eco-systems: an epochal review of practice-oriented research. Int J Inform Manage 2020; 53: 102032.27

31. Cranefield J, Yoong P. Organisational factors affecting inter-organisational knowledge transfer in the New Zealand state sector: a case study. https:// openaccess.wgtn.ac.nz/articles/journal_contribution/Organisational_factors_affecting_inter-organisational_knowledge_transfer_in_the_New_Zealand_state_sector_a_case_study/12910031/1 Accessed March 01, 2021.

32. Almeida P, Kogut B. Localization of knowledge and the mobility of engineers in regional networks. Manag Sci 1999; 45 (7): 905-17. Jul

33. Rosenkopf L, Almeida P. Overcoming local search through alliances and mobility. Manag Sci 2003; 49 (6): 751-66. Jun

34. Nonaka I, Byosiere P, Borucki CC, Konno N. Special issue knowledge in organizations, knowledge transfer and cooperative strategies organizational knowledge creation theory: a first comprehensive test. Int Bus Rev 1994; 3 (4): 337-51.

35. Gupta AK, Govindarajan V. Knowledge flows within multinational corporations. Strat Mgmt J 2000; 21 (4): 473-96.

36. Inkpen AC, Dinur A. Knowledge management processes and international joint ventures. Organ Sci 1998; 9 (4): 454-68. 
37. Larsson R, Bengtsson L, Henriksson K, Sparks J. The interorganizational learning dilemma: collective knowledge development in strategic alliances. Organization Science 1998; 9 (3): 285-305. Jun

38. Retzer S, Yoong P, Hooper V. Inter-organisational knowledge transfer in social networks: a definition of intermediate ties. Inf Syst Front 2012; 14 (2): 343-61. Apr

39. Battistella C, De Toni AF, Pillon R. Inter-organisational technology/ knowledge transfer: a framework from critical literature review. J Technol Transf 2016; 41 (5): 1195-234. Oct 1

40. Cresswell K, Sheikh A, Krasuska M, et al. How can health services establish digital health learning ecosystems? Insights from a qualitative evaluation of a national digital health change programme in English provider organisations (under review in JMIR). A previous version of this paper is available from: https://www.ed.ac.uk/files/atoms/files/30_month_gde_ evaluation_report_0.pdf Accessed March 01, 2021.

41. Digitial Health. Digital Health Networks is the Largest Community of NHS IT Leaders. https://www.digitalhealth.net/join-the-digital-healthnetworks/Accessed August 01, 2020

42. National Health Service. NHS Digital Academy. https://www.england. nhs.uk/digitaltechnology/nhs-digital-academy/Accessed January 8 , 2020 .

43. National Health Service. So, what is a Local Health and Care Record anyway? https://digital.nhs.uk/blog/transformation-blog/2019/so-what-is-alocal-health-and-care-record-anyway Accessed August 01, 2020.

44. National Health Service. What are Integrated Care Systems? https://www.england.nhs.uk/integratedcare/integrated-care-systems/ Accessed August 01, 2020 